\title{
IMPLEMENTASI FSM (FINITE STATE MACHINE) PADA GAME PERJUANGAN PANGERAN DIPONEGORO
}

\author{
Dhebys Suryani Hormansyah ${ }^{1}$, Ariadi Retno Tri Hayati Ririd², Dedy Teguh Pribadi ${ }^{3}$ \\ Program Studi Teknik Informatika, Jurusan Teknologi Informasi, Politeknik Negeri Malang \\ dhebys.suryani@gmail.com ${ }^{1}$, ariadi.retno@polinema.ac.id ${ }^{2}$, deddyteguh211@gmail.com³
}

\begin{abstract}
Abstrak
Ilmu teknologi hari demi hari semakin menunjukkan perkembangan di berbagai bidang, teknologi game adalah salah satunya. Game adalah permainan yang menggunakan media elektronik, merupakan sebuah hiburan berbentuk multimedia yang di buat semenarik mungkin agar pemain bisa mendapatkan sesuatu sehingga adanya kepuasan batin. Bermain game juga merupakan salah satu saran pembelajaran. Generasi masa kini tampaknya lebih menikmati kebudayaan moderen dibanding sejarah. Salah satu faktor yang menyebabkan generasi muda Indonesia kurang paham akan sejarah kepahlawanan adalah kurang ditanamkannya rasa nasionalisme dan pengetahuan mengenai pahlawan Indonesia. Pangeran Diponegoro adalah sosok penting dalam sejarah Indonesia. Dialah yang menjadi penggerak utama perlawanan rakyat pada masa pendudukan Belanda di abad ke-18. Keterlibatan yang masif dari masyarakat Jawa dalam mendukung Pangeran Diponegoro menjadikan perlawanan ini sebagai salah satu perang besar yang harus diahadapi Belanda yang disebut sebagai Perang Jawa. Dibuatlah aplikasi game edukasi dengan mengangkat tokoh pahlawan Pangeran Diponegoro. Pada aplikasi ini akan diimplementasikan kecerdasan buatan dengan metode Finite State Machine (FSM) dimana akan mempermudah mengatur perilaku dari objek saat terjadi perubahan keadaan atau kondisi dalam permainan. Seiring dengan berkembangnya game, seseorang lebih memilih untuk memanfaatkan mobile device sebagai salah satu sarana bermain game, dimana aplikasi ini akan menggunakan sistem operasi Android. Aplikasi ini dibangun sebagai sarana hiburan dan edukasi mengenal lebih dekat tentang tokoh pahlawan Pangeran Diponegoro.
\end{abstract}

Kata kunci : kecerdasan buatan, finite state machine $\left(f_{S m}\right)$, edukasi

\section{Pendahuluan}

Perkembangan ilmu teknologi hari demi hari semakin menunjukkan perkembangan di berbagai bidang, teknologi game adalah salah satunya. Game adalah permainan yang menggunakan media elektronik, merupakan sebuah hiburan berbentuk multimedia yang di buat semenarik mungkin agar pemain bias mendapatkan sesuatu sehingga adanya kepuasan batin. Bermain game juga merupakan salah satu saran pembelajaran. Game edukasi dibuat denga tujuan spesifik sebagai alat pendidikan seperti untuk belajar mengenal warna, mengenal huruf dan angka, matematika, sampai belajar bahasa asing.

10 November diperingati sebagai Hari Pahlawan. Biasanya, Hari Pahlawan diisi dengan beragam acara bertujuan mengingatkan atas kegigihan para pahlawan dalam memperjuangkan dan mempertahankan kemerdekaan. Kemerdekaan yang telah diraih sejak 72 tahun silam terkadang membuat generasi muda lupa dengan sejarah. Generasi masa kini tampaknya lebih menikmati kebudayaan moderen dibanding sejarah. Salah satu faktor yang menyebabkan generasi muda Indonesia kurang paham akan makna Hari Pahlawan adalah kurang ditanamkannya rasa nasionalisme dan pengetahuan mengenai pahlawan Indonesia. Pangeran Diponegoro adalah sosok penting dalam sejarah Indonesia. Dialah yang menjadi penggerak utama perlawanan rakyat pada masa pendudukan Belanda di abad ke-18. Keterlibatan yang masif dari masyarakat Jawa dalam mendukung Pangeran Diponegoro menjadikan perlawanan ini sebagai salah satu perang besar yang harus diahadapi Belanda yang disebut sebagai Perang Jawa.

Dari permasalahan tersebut, penulis akan membangun sebuah aplikasi game edukasi dengan mengangkat tokoh pahlawan Pangeran Diponegoro. Pada aplikasi ini akan diimplementasikan kecerdasan buatan dengan metode Finite State Machine (FSM) dimana akan mempermudah mengatur perilaku dari objek saat terjadi perubahan keadaan atau kondisi dalam permainan. Seiring dengan berkembangnya game, seseorang lebih memilih untuk memanfaatkan mobile device sebagai salah satu sarana bermain game, dimana aplikasi ini akan menggunakan sistem operasi Android. Aplikasi ini dibangun sebagai sarana hiburan dan edukasi mengenal lebih dekat tentang tokoh pahlawan Pangeran Diponegoro.

\section{Kajian Pustaka}

\subsection{Implementasi}

Implementasi adalah bermuara pada aktivitas, aksi, tindakan, atau adanya mekanisme suatu sistem. 
Implementasi bukan sekedar aktivitas, tetapi suatu kegiatan yang terencana dan untuk mencapai tujuan kegiatan (Usman, 2012).

\subsection{FSM (Finite State Machine)}

Finite State Machine (FSM) merupakan sebuah mesin abstrak yang berfungsi untuk mendefinisikan sekumpulan kondisi yang menentukan kapan suatu state harus berubah. Setiap state yang sedang dijalankan tersebut menentukan perilaku yang terjadi pada objek yang bersangkutan. Diagram state FSM digambarkan pada gambar 1 sebagai berikut, (Feisal, 2015).

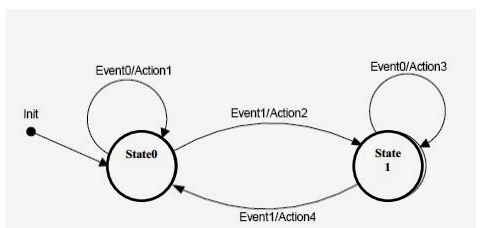

Gambar 1. Skema Finite State Machine

\subsection{Game}

Permainan adalah semua alat bermain yang dapat digunakan oleh peserta didik untuk memenuhi naluri bermainnya dan memiliki barbagai macam sifat, seperti bongkar pasang, mengelompokkan, memadukan, mencari padanannya, merangkai, membentuk, atau menyusun sesuai dengan bentuk aslinya. (Marimin, 2004)

\subsection{Kecerdasan Buatan}

Kecerdasan adalah kemampuan untuk belajar dan mengerti dari pengalaman, memahami pesan yang kontradiktif dan ambigu, menanggapi dengan cepat dan baik atas situasi yang baru, menggunakan penalaran dalam memecahkan masalah serta menyelesaikannya dengan efektif. (Suparman, 1991)

\subsection{Definisi Story Board}

Storyboard adalah kolom teks, audio dan visualisasi dengan keterangan mengenai content dan visualisasi yang digunakan untuk produksi sebuah course. Derajat Storyboard bisa berbeda karena ada berbagai tahap yang harus dilalui sesuai tujuan pembuatan Storyboard tersebut.

\subsection{Unity Game Engine}

Unity 3D ini digunakan sebagai media pembuatan Aplikasi Implementasi FSM (Finite State Machine) dari pembuatan setiap objeknya sampai penyelesaian pembuatan game. Penulis menggunakan software Unity 3D ini karena unity memiliki banyak tools yang dapat digunakan untuk membuat latar dan pengoperasiannya (Roedavan, 2014).

\subsection{Adobe Illustrator}

Adobe Illustrator merupakan aplikasi untuk mengolah serta mengedit desain atau gambar vektor, dimana aplikasi ini dikembangkan dan dipasarkan oleh Adobe Systems. Adobe Illustrator tersedia di komputer, yang berarti aplikasi ini tidak bisa digunakan di perangkat lain seperti handphone, tablet, dan perangkat lainnya (Baidowi, 2015).

\subsection{Pengenalan Android}

Android adalah sebuah sistem operasi untuk perangkat mobile yang mencakup sistem operasi, middleware dan aplikasi. Android menyediakan platform terbuka bagi para pengembang untuk menciptakan aplikasi mereka. Awalnya, Google Inc. membeli Android Inc. yang merupakan pendatang baru pembuat perangkat lunak untuk ponsel/smartphone dengan membentuk Open Handset Alliance (OHA) Pada saat perilisan perdana Android, 5 November 2007, Android bersama OHA menyatakan mendukung pengembangan open source pada perangkat mobile.

\section{Metode Penelitian}

Dalam metode penelitian ini akan dijelaskan langkah-langkah yang dilakukan untuk merancang game Perjuangan Pangeran Diponegoro sebagai berikut:

\subsection{Studi Literatur}

Studi literatur ini sebagai dasar teori yang akan melandasi pengerjaan aplikasi ini.

\subsection{Metode Pengumpulan Data}

Tahapan pengumpulan data ini dilakukan untuk memperoleh data dan informasi yang diperlukan dalam pembuatan aplikasi.

\subsection{Metode Pengembangan}

Metode yang digunakan adalah metode Multimedia Development Life Cycle (MDLC). Dimana metode ini terdiri dari beberapa fase yaitu konsep (concept), design (design), pengumpulan bahan (material collecting), pembuatan (assembly), pengujian (testing), dan distribusi (distribution).

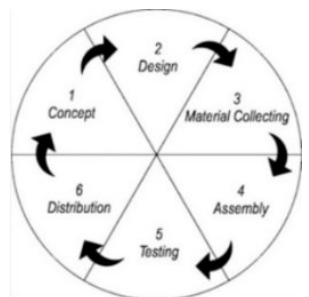

Gambar 2. Diagram Multimedia Development Life Cycle

1) Konsep (Concept)

Konsep game edukasi ini menceritakan kepahlawanan Pangeran Diponegoro, dimana player melakukan perjalanan mencapai untuk mencapai finish. Pada setiap chapter / state terdapat NPC yang diimplementasikan kecerdasan buatan dengan metode FSM.

2) Desain (Design) 
Setelah penentuan konsep, maka dibuat alur dan perancangan game berupa WBS, dan Storyboard. Pada tahap ini juga dilakukan proses penentuan karakter dan objek yang akan dibuat pada game.

3) Pengumpulan Bahan (Material Collecting) Tahap ini adalah proses pengumpulan bahan yang sesuai dengan kebutuhan system game. Adapaun bahan- bahan yang dibutuhkan adalah sebagai berikut :

a. Gambar tombol, icon game, animasi dan lain-lain. Pembuatan gambar menggunakan aplikasi Adobe Illustrator

b. Audio yang diperlukan adalah backsound music dan sound effect.

c. Animasi obyek yang digunakan adalah animasi pada karakter.

4) Pembuatan (Assembly)

Setelah mengumpulkan bahan-bahan yang sudah ada, dilakukan pengolahan menggunakan engine Unity. Pembuatan sistem game dan implementasi dilaksanakan ditahap ini beserta pengkodingan.

5) Pengujian (Testing)

Pengujian dilakukan dengan menggunakan metode White Box dan metode Black Box:

- Metode pengujian White Box menggunakan struktur kontrol desain prosedural (structural testing) untuk memperoleh test case. Pengujian ini mengasumsikan bahwa logik spesifik adalah penting dan harus diuji untuk menjamin sistem melakukan fungsi dengan benar.

- Metode pengujian Black Box merupakan pengujian user interface kepada pengguna apakah sistem dapat dioperasikan atau tidak. Pengujian ini dilakukan dengan memberikan data sample sebagai nilai masukan dan dibandingkan dengan informasi yang dihasilkan, disebut juga pengujian berbasis skenario.

6) Distribusi (Distribution)

Pada tahap ini, project yang telah selesai kemudian dilakukan pemaketan aplikasi. Dalam game ini akan di distribusikan ke dalam Play Store, dengan tujuan agar pengguna dapat dengan mudah mengakses aplikasi.

\section{Analisis dan Perancangan}

\subsection{Gambaran Umum Aplikasi}

Gambaran umum dari aplikasi Implementasi FSM (Finite State Machine) pada Game Perjuangan Pangeran Diponegoro antara lain,

- Apliaksi in dimainkan oleh satu orang saja atau Single Player

- Aplikasi ini berbasis android

- Aplikasi menerapkan FSM (Finite State Machine)

\subsection{Analisis Kebutuhan}

a. Hardware

- Asus K401uq

- Processor Intel Core i5 7th generation

- VGA GT 940MX

- RAM 8Gb

b. Software

- Adobel Illustrator CC 2017

- Unity 3d 5.3.1

\subsection{Perancangan Aplikasi}

a. Work Breakdown Structure

Pada Pembuatan ini Struktur kerja yang akan diterapkan pada aplikasi ini menggunakan konsep dan alur dari Multimedia Development Life Cycle dan dijabarkan sesuai dengan pekerjaan yang harus dikerjakan saat pembuatan aplikasi ini. Berikut WBS yang di gambarkan pada gambar 3.

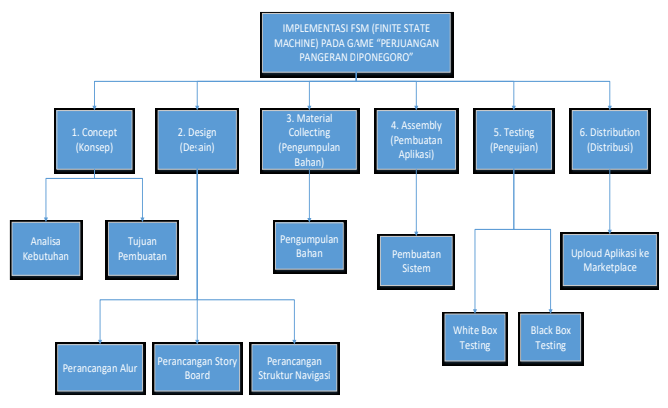

Gambar 3. Work Breakdown Structure

b. Sitemap Mobile

Sitemap mobile merupakan salah satu cara sederhana untuk menginformasikan kepada pengguna tentang halaman-halaman pada aplikasi. Pada Gambar 4 menampilkan bagaimana bentuk sitemap mobile aplikasi ini.

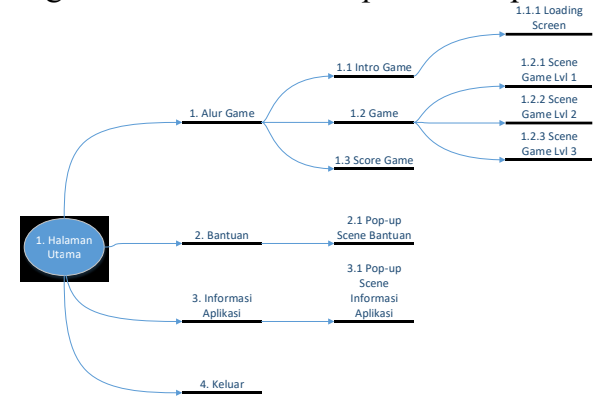

Gambar 4. Sitemap Mobile

c. Use Case Diagram

Us case pada aplikasi berhubungan dengan interaksi user terhadap sistem. Diagram usecase pada gambar 5 dilakukan oleh actor sebagai User yang menggambarkan bagaimana actor dapat menjalankan fungsi-fungsi yang terdapat pada aplikasi. 


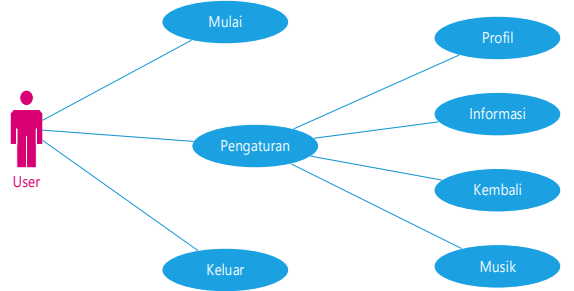

Gambar 5. Use Case Diagram

\section{d. Storyboard}

Berikut ini alur implementasi FSM (Finite State Machine) pada game perjuangan pangeran diponegoro dalam bentuk storyboard pada tabel 1 ,

Tabel 1, Storyboard

\begin{tabular}{|l|l|}
\hline Kambar & $\begin{array}{l}\text { Kaderangan awal permainan akan } \\
\text { muncul menu awal terdapat } \\
\text { menu mulai, keluar, dan } \\
\text { pengaturan }\end{array}$ \\
\hline PERJUANGAN \\
\hline PANGRAN
\end{tabular}

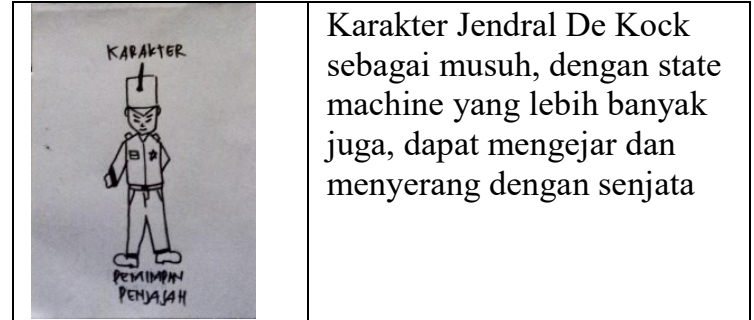

e. Penerapan Metode FSM (Finite State Machine)

- Pada Tabel 2 berikut ini menjelaskan rancangan alur state Finite State Machine permainan perjuangan pangeran diponegoro pada musuh shooter yang terdiri dari state (Q), event (e), dan action (a).

Tabel 2, Rancangan Alur State FSM Shooter

\begin{tabular}{|c|c|c|c|}
\hline $\begin{array}{c}\text { Current } \\
\text { State }(Q)\end{array}$ & Event (e) & Action (a) & $\begin{array}{c}\text { State } \\
\text { Transition }\end{array}$ \\
\hline Idle & $\begin{array}{l}\text { Jika jarak } \\
\text { musuh } \\
\text { dengan } \\
\text { player } x< \\
16\end{array}$ & $\begin{array}{l}\text { Perilaku } \\
\text { objek } \\
\text { musuh Idle }\end{array}$ & Idle \\
\hline Idle & $\begin{array}{l}\text { Jika } \\
\text { indikator } \\
\text { jarak musuh } \\
\text { dengan } \\
\text { player } \\
x>16 \text { dan } \\
y<9\end{array}$ & $\begin{array}{l}\text { Perilaku } \\
\text { objek } \\
\text { musuh } \\
\text { Run }\end{array}$ & Run \\
\hline Idle & $\begin{array}{l}\text { Jika jarak } \\
\text { musuh } \\
\text { dengan } \\
\text { player } x<9\end{array}$ & $\begin{array}{l}\text { Perilaku } \\
\text { objek } \\
\text { musuh } \\
\text { Shot }\end{array}$ & Shot \\
\hline Idle & $\begin{array}{l}\text { Jika nyawa } \\
\text { musuh } \\
\text { shooter }<=0\end{array}$ & $\begin{array}{l}\text { Objek } \\
\text { musuh } \\
\text { Death }\end{array}$ & Death \\
\hline Run & $\begin{array}{l}\text { Jika nyawa } \\
\text { musuh } \\
\text { shooter }<=0\end{array}$ & $\begin{array}{l}\text { Objek } \\
\text { musuh } \\
\text { Death }\end{array}$ & Death \\
\hline Run & $\begin{array}{l}\text { Jika jarak } \\
\text { musuh } \\
\text { dengan } \\
\text { player } x< \\
16 \text { dan } y> \\
9\end{array}$ & $\begin{array}{l}\text { Perilaku } \\
\text { objek } \\
\text { musuh Idle }\end{array}$ & Idle \\
\hline Shot & $\begin{array}{l}\text { Jika nyawa } \\
\text { musuh } \\
\text { shooter }<=0\end{array}$ & $\begin{array}{l}\text { Objek } \\
\text { musuh } \\
\text { Death }\end{array}$ & Death \\
\hline Shot & $\begin{array}{l}\text { Jika jarak } \\
\text { musuh } \\
\text { dengan } \\
\text { player } x< \\
9\end{array}$ & $\begin{array}{l}\text { Perilaku } \\
\text { objek } \\
\text { musuh Idle }\end{array}$ & Idle \\
\hline
\end{tabular}

Keterangan :

- State (Q) adalah keadaan

- $\quad$ Event (e) adalah kondisi

- Action (a) adalah aksi, 
Pada gambar 6 menerangkan transisi setiap state dari tabel 2.

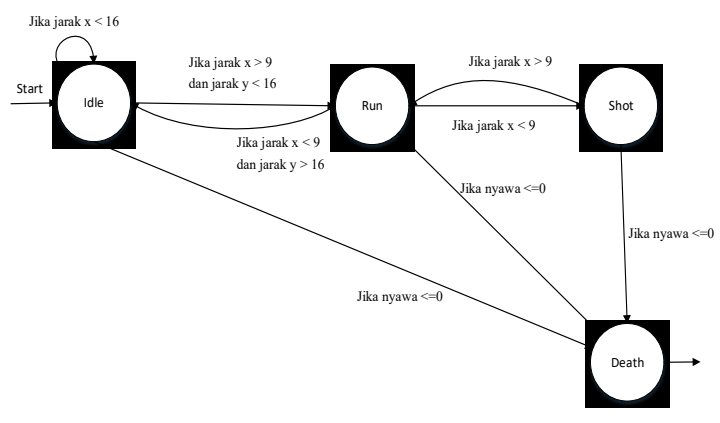

Gambar 6. Diagram State dan Transisi

Keterangan :

- (x) adalah garis horizontal

- (y) adalah garis vertikal

Pada gambar 7 merupakan keterangan posisi musuh dengan player.

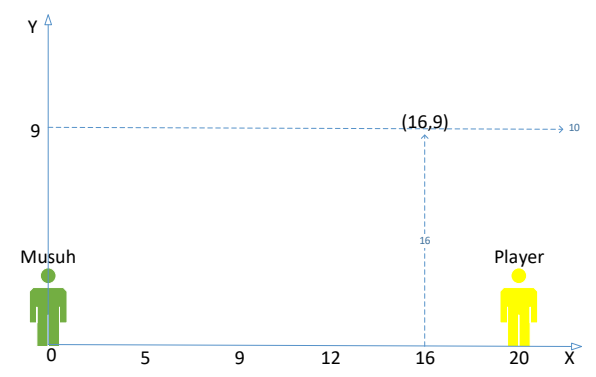

Gambar 7. Posisi Musuh dan Player

- Pada Tabel 3 berikut ini menjelaskan rancangan alur state Finite State Machine permainan perjuangan pangeran diponegoro pada musuh shooter yang terdiri dari state $(\mathrm{Q})$, event (e), dan action (a).

Tabel 3, Rancangan Alur State FSM Shooter

\begin{tabular}{|c|c|c|c|}
\hline $\begin{array}{c}\text { Curren } \\
\text { State }(Q)\end{array}$ & $\begin{array}{c}\text { Event } \\
\text { (e) }\end{array}$ & Action (a) & $\begin{array}{c}\text { State } \\
\text { Transition }\end{array}$ \\
\hline Idle & $\begin{array}{l}\text { Jika } \\
\text { jarak } \\
\text { musuh } \\
\text { dengan } \\
\text { player } x \\
<16\end{array}$ & $\begin{array}{l}\text { Perilaku } \\
\text { objek } \\
\text { musuh Idle }\end{array}$ & Idle \\
\hline Idle & $\begin{array}{l}\text { Jika } \\
\text { indikator } \\
\text { jarak } \\
\text { musuh } \\
\text { dengan } \\
\text { player } x \\
>16 \text { dan } \\
y<9\end{array}$ & $\begin{array}{l}\text { Perilaku } \\
\text { objek } \\
\text { musuh } \\
\text { JumpAttack }\end{array}$ & JumpAttack \\
\hline
\end{tabular}

\begin{tabular}{|l|l|l|l|}
\hline JumpAttack & $\begin{array}{l}\text { Jika } \\
\text { jarak } \\
\text { musuh } \\
\text { dengan } \\
\text { player } \mathrm{x} \\
<16 \text { dan } \\
\mathrm{y}>9\end{array}$ & $\begin{array}{l}\text { Perilaku } \\
\text { objek } \\
\text { musuh Idle }\end{array}$ & \\
& & \\
& & \\
\hline JumpAttack & $\begin{array}{l}\text { Jika } \\
\text { nyawa } \\
<=0\end{array}$ & $\begin{array}{l}\text { Objek } \\
\text { musuh } \\
\text { Death }\end{array}$ & Death \\
\hline
\end{tabular}

\section{Analisis dan Perancangan}

Pembuatan asset karakter dan onjek pada aplikasi menggunakan Adobe Illustrator CC 2017

a. Implementasi Objek, Karakter, dan Animasi

- Proses pembuatan asset desain karakter diponegoro diam, jalan, terkena serangan, shot, loncat, serang, dan mati digambarkan pada pada gambar 8 .

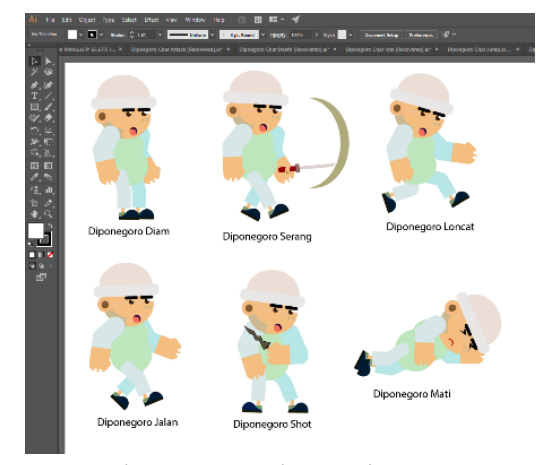

Gambar 8. Karakter Diponegoro

- Proses pembuatan asset desain karakter musuh shooter diam, jalan, terkena serangan, menembak dan mati digambarkan pada pada gambar 9/

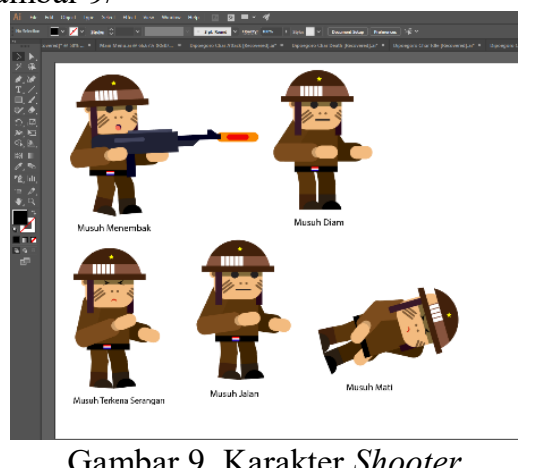

Gambar 9. Karakter Shooter

- Proses pembuatan asset desain karakter jumper diam, lari, mendapatkan serangan, dan mati digambarkan pada pada gambar 10 


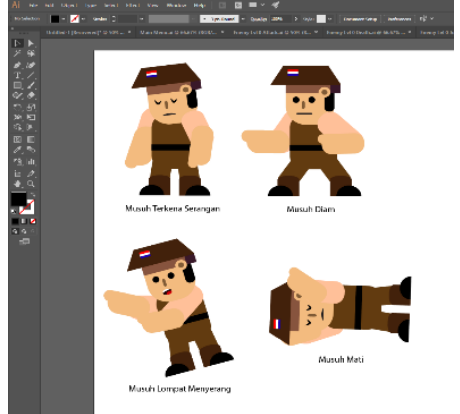

Gambar 10. Karakter Jumper

b. Implementasi Antar Muka

- Pada gambar 11 merupakan tampilan awal, dimana teradapat backround judul game, tombol mulai, tombol exit dan tombol pengaturan.

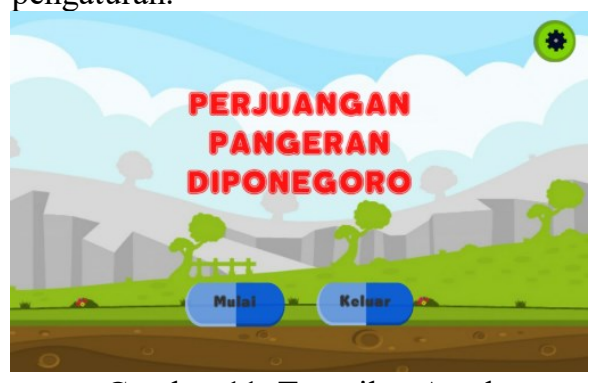

Gambar 11. Tampilan Awal

- Pada gambar 12 merupakan tampilan dari halaman permainan pada level 1. Pemain harus mencari bendera atau garis finish agar dapat melanjutkan ke level berikutnya

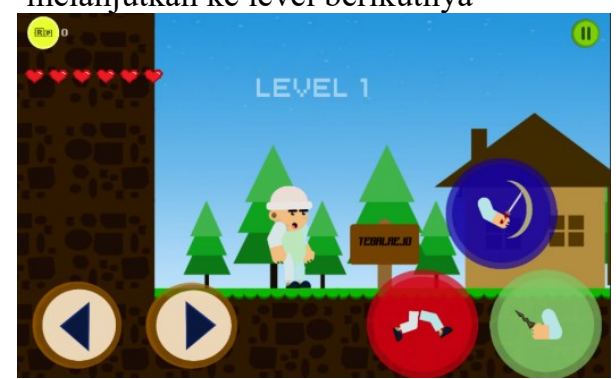

Gambar 12. Tampilan Level

\section{c. Implementasi Metode FSM}

a. Diagram State Musuh Shooter

Gambar 13 berikut merupakan diagram state permainan perjuangan pangeran diponegoro pada musuh lvl 2 dengan penerapan kecerdasan buatan Finite State Machine (FSM).

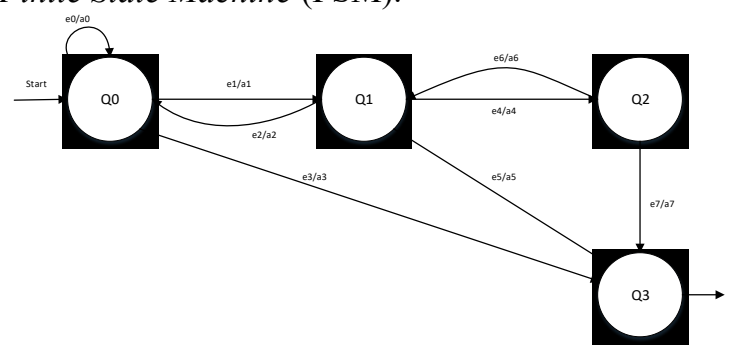

Gambar 13. FSM Shooter
Keterangan :

- $\quad$ State (Q) adalah keadaan

- Event (e) adalah kondisi

- Action (a) adalah aksi

Berikut keterangan setiap lambang yang ada pada gambar 13 dalam bentuk tabel,

Tabel 4, Penjelasan Keterangan Diagram State Musuh Shooter

\begin{tabular}{|c|l|}
\hline Lambang & \multicolumn{1}{|c|}{ Penjelasan } \\
\hline Q0 & State Idle dilambangkan (Q0) \\
\hline Q1 & State Run dilambangkan (Q1) \\
\hline Q2 & State Shot dilambangkan (Q2) \\
\hline Q3 & State Death dilambangkan (Q3) \\
\hline e0/a0 & Event 0 (e0) dan action 0 (a0) \\
\hline e1/a1 & Event 1 (e1) dan action 1 (a1) \\
\hline $\mathrm{e} 2 / \mathrm{a} 2$ & Event 2 (e2) dan action 2 (a2) \\
\hline $\mathrm{e} 3 / \mathrm{a} 3$ & Event 3 (e3) dan action 3 (a3) \\
\hline $\mathrm{e} 4 / \mathrm{a} 4$ & Event 4 (e4) dan action 4 (a4) \\
\hline $\mathrm{e} 5 / \mathrm{a} 5$ & Event 5 (e5) dan action 5 (a5) \\
\hline $\mathrm{e} 6 / \mathrm{a} 6$ & Event 6 (e6) dan action 6 (a6) \\
\hline $\mathrm{e} 7 / \mathrm{a} 7$ & Event 7 (e7) dan action 7 (a7) \\
\hline
\end{tabular}

Tabel 5, Tabel Transisi

\begin{tabular}{|c|c|c|c|c|}
\hline \multirow{10}{*}{ Event (e) / Action (a) } & \multicolumn{4}{|c|}{ Tabel Transisi } \\
\hline & State & Q0 & Q1 & Q2 \\
\hline & $\mathbf{0}$ & Q0 & Q1 & $\mathrm{Q} 2$ \\
\hline & 1 & Q1 & Q1 & Q2 \\
\hline & 2 & Q0 & Q0 & Q2 \\
\hline & 3 & Q3 & Q1 & Q2 \\
\hline & 4 & Q0 & Q2 & Q0 \\
\hline & 5 & Q0 & Q3 & Q2 \\
\hline & 6 & Q0 & Q1 & Q1 \\
\hline & 7 & Q0 & Q1 & Q3 \\
\hline
\end{tabular}

Source Code Metode FSM Shooter

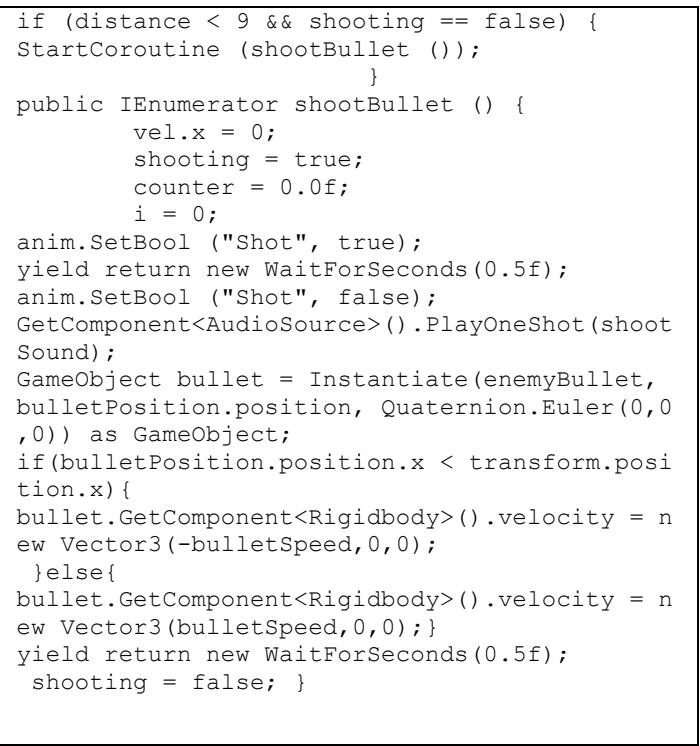


b. Diagram State Musuh Jumper

Gambar 15 berikut merupakan diagram state permainan perjuangan pangeran diponegoro pada musuh jumper dengan penerapan kecerdasan buatan Finite State Machine (FSM).

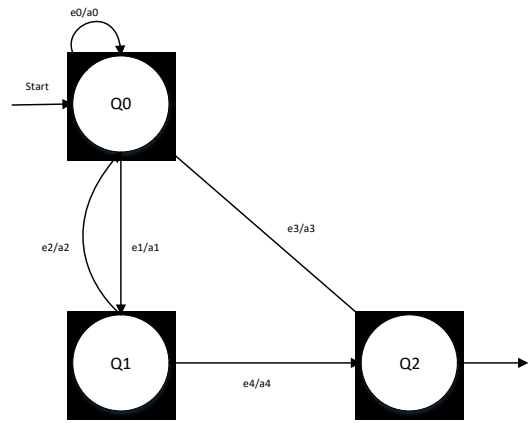

Gambar 14. FSM Jumper

- Tabel Transisi Diagram State Musuh Shooter

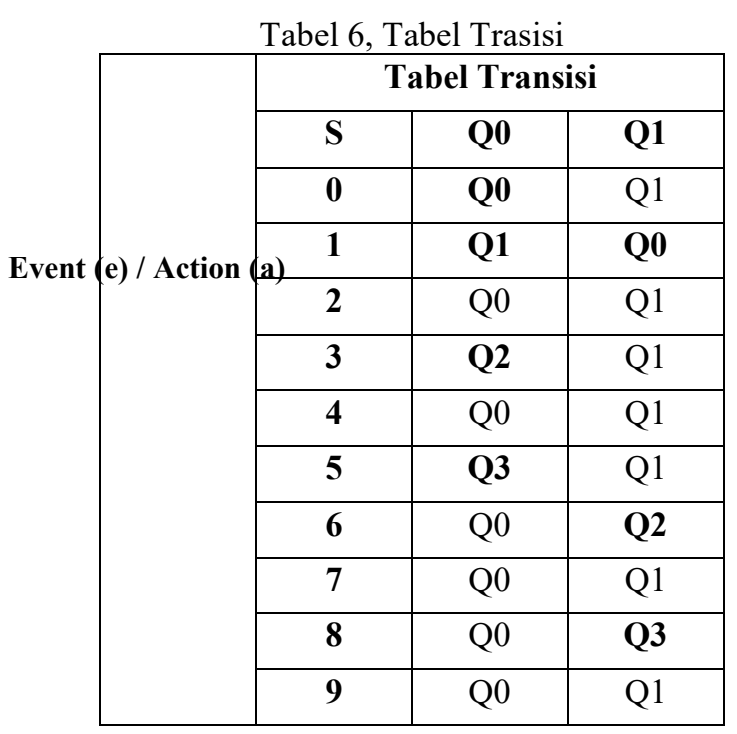

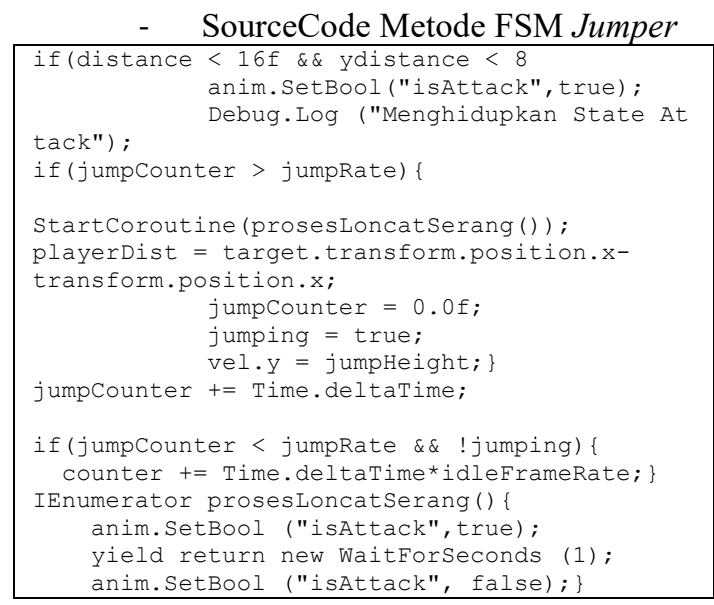

\section{Implementasi dan Pembahasan}

a. Pengujian Black Box

Rencana pengujian akan dilakukan sistem aplikasi, pengujian dilakukan dengan teknik pengujian BlackBox. Pengujian BlackBox memfokuskan pada keperluan fungsional dari perangkat lunak.

\section{b. Pengujian Alpha}

Berdasarkan rencana pengujian, maka dapat dilakukan pengujian alpha pada permainan perjuangan pangeran diponegoro

c. Pengujian Beta

Pengujian beta merupakan pengujian yang dilakukan dengan tujuan untuk mengetahui bagaimana kualitas sistem yang telah dibuat. Dalam pengujian beta dilakukan terhadap responden atau calon pengguna sistem dengan menggunakan kuesioner,

\section{Kesimpulan dan Saran}

Setelah melakukan analisis, perancangan dan pengkajian maka dapat diperoleh kesimpulan sebagai berikut :

a. Pada penelitian yang sudah dilaksanakan pada aplikasi implementasi metode FSM (Finite State Machine) pada game perjuangan pangeran diponegoro dapat diambil keputusan bahwa penerapan metode FSM ini dapat menentukan perilaku NPC (Non Character Player), maka dengan ini metode FSM dapat memberikan pengaruh terhadat aksi pengguna terhadap sistem. Pada kuisoner yang telah dibagikan kepada 5 responden dengan memberikan 7 pertanyaan seputar aplikasi didapatkan rata - rata prosentase kuisoner sebanyak $83 \%$, sehingga aplikasi ini dapat digunakan sebagai media permainan edukasi.

b. Penelitian masih dapat dikembangkan menjadi aplikasi game yang lebih kompleks lagi dalam pembuatan karakter, asset, tiles dan animasi yang lebih baik.

c. Juga dapat dengan penerapan metode FSM pada NPC yang lebih banyak lagi.

d. Menambah level lebih banyak lagi dari sebelumnya

e. Game ini juga dapat dikembangkan dengan menambahkan metode lain.

\section{DAFTAR PUSTAKA}

Abdullah Dahlan dkk, "Game Edukasi Berbasis Role Playing Dengan Metode Finite State Machine”, Aceh : Universitas Malikussaleh Reuleut, 2015.

Abdullah Dahlan, dkk, Penerapan Metode Finite State Machine Pada Game "The Relationship".Samarinda, Kalimantan Timur. Jurnal Informatika Mulawarman, 2016.

Ardison MS, Diponegoro Dan Perang Jawa, Surabaya, Ecosystem Publishing, 2017.

Baidowi, Ardilas(2015, Sept 20). Pengertian Dari Adobe Ilustrator (AI). [Online] Tersedia: http://www.ardilas.com/2015/05/apakah-itudefinisi-pengertiandari-software-aplikasi-adobeillustrator-adalah-merupakan.html

Feisal, ferdian, Pengembangan FSM Untuk Memodelkan Agen Dan Pergerakan Olahraga Futsal. Bogor: Institute Pertanian Bogor, 2015. 
Fidiyanto Dwi, dkk, Game Sejarah Perjuangan Kapitan Patimura Berbasis Android.Kudus, Jawa Tengah. Teknik Informatika Fakultas Teknik Universitas Muria Kudus, 2015.

Marimin, "Teknik dan Aplikasi Pengambilan keputusan Kriteria Majemuk”, 2004.

Rahadian, Miftah Fauzan dkk. 2016. "Penerapan Metode Finite State Machine Pada Game "The Relationship". Samarinda : Universitas Mulawarman", 2016.

Roedavan, Rickman, Unity Tutorial Game Engine. Bandung: Informatika Bandung, 2014.

Rostianingsih, Silvia dkk, Game Simulasi Finite State Machine Untuk Pertanian dan Peternakan. Surabaya : Universitas Kristen Petra, 2011.

Setiawan, "Perancangan Software Embedded System Berbasis FSM”, 2006.

Suparman, "Mengenal Artificial Intelligence”, Andi Offset, Yogyakarta, 1991.

Usman, Nurdin.. "Konteks Implementasi Berbasis Kurikulum”, 2012 